\title{
ESTIMATIVA DO CUSTO DO ABASTECIMENTO DE ÁGUA BASEADO NO CONSUMO DE ENERGIA: ESTUDO DE CASO NA UFPB
}

\author{
ESTIMATION OF THE COST OF WATER SUPPLY BASED ON ENERGY \\ CONSUMPTION: CASE STUDY AT UFPB
}

Anderson Karlo Fernandes Vieira' Eládio José de Góes Brennand²

\section{RESUMO}

Este trabalho faz uma investigação relativa ao consumo de água subterrânea captada por meio de poços artesianos que são utilizados para abastecimento da UFPB no seu Campus I. A determinação do consumo é necessária, pois não existem dispositivos de medições que permitam conhecer a quantidade de água captada dos poços. Sendo assim, este volume foi determinado através de inferências entre o gasto do consumo de energia elétrica relacionada ao funcionamento dos motores que recalcam o fluido, medido por meio de equipamento apropriado durante um período de 30 dias, e o valor do metro cúbico de água da concessionária local. Verificou-se que o consumo de energia neste período foi de 3.885,50 kWh, equivalendo a volume de água aduzida de 12.781,50 $\mathrm{m}^{3}$. Utilizou-se como parâmetro comparativo o sistema de abastecimento da UFCG a qual possui um custo anual para abastecimento de $R \$ 23,67$ /aluno matrículado, já na UFPB possui $R \$ 184,81$ / aluno matrículado. A partir do conhecimento do volume de água consumida, pode-se propor medidas gerenciais de combate, controle e operacionalização do sistema, a fim de evitar perdas desse precioso líquido, bem como promover o uso sustentável dos recursos hídricos disponíveis.

Palavras-chave: Consumo. Abastecimento de água. Sustentabilidade. Poços artesianos. Energia elétrica. Custo.

\section{ABSTRACT}

This work investigates the consumption of groundwater collected through artesian wells that are used to supply the UFPB in its Campus I. The determination of the consumption is necessary, since there are no measurement devices that allow to know the amount of water abstracted of wells. Thus, this volume was determined

1 Mestrando em Gestao nas Organizações Aprendentes pela Universidade Federal da Paraíba (UFPB). E-mail: andersonkarlo@ hotmail.com.br

2 Doutor em Ciências e Pós-Doutor pela Université Libre de Bruxelles (ULB). Docente da Universidade Federal da Paraiba (UFPB). E-mail: eladiobrennand@uol.com.br 
through inferences between the consumption of electric energy related to the operation of the engines that stress the fluid, measured by means of appropriate equipment during a period of 30 days, and the value of the cubic meter of water of the local dealer. It was verified that the consumption of energy in this period was $3,885.50 \mathrm{kWh}$, equivalent to the volume of water added of $12,781.50 \mathrm{~m}^{3}$. Was used as a comparative parameter the UFCG supply system which has an annual cost of supply of $R \$ 23.67$ / enrolled student, while the UFPB has a $R \$ 184.81$ / enrolled student. From the knowledge of the volume of water consumed, it is possible to propose management measures to combat, control and operationalize the system in order to avoid losses of this precious liquid, as well as to promote the sustainable use of available water resources.

Keywords: Consumption. Water supply. Sustainability. Artesian wells. Electricity. Cost.

\section{INTRODUÇÃO}

A disponibilidade de água no planeta é um fator imprescindível para o desenvolvimento dos seres vegetais e animais, além disso, ela é essencial para a higiene e o bem-estar humanos, bem como elemento decisivo para o progresso econômico e social.

De acordo com Lemos (2003), embora a água seja um recurso renovável, sua quantidade é limitada, não estando distribuída de forma proporcional à população existente, a quantidade de água disponível já chega perto do limite: 40\% da população mundial já sofrem de escassez de água. Para satisfazer à demanda de água, a humanidade tem modificado o ciclo hidrológico desde o início de sua história, mediante construção de poços, de barragens, de açudes, de aquedutos, de sistemas de abastecimento, de sistemas de drenagem, de projetos de irrigação e de outras estruturas.

Atualmente, pouco se sabe sobre do consumo real de água no dentro do Campus I da UFPB, apenas a parcela referente à CAGEPA é quantificada, medida e valorada a outra parcela, tão importante quanto à primeira, não é mensurada, e não sendo mensurada não há conhecimento do real valor do serviço fornecido. Portanto, pretende-se determinar o custo de energia associado à captação de água dos poços artesianos responsáveis pelo abastecimento da UFPB no Campus I e através deste valor estimar o volume de água extraído dos poços para o abastecimento.

O desenvolvimento da pesquisa se justifica, pois a UFPB desconhece o consumo de água no Campus. Esse desconhecimento se dá porque existem fontes de fornecimento de água alternativa, poços artesianos, para suprir as demandas necessárias ao funcionamento institucional. Esse obscurantismo faz com que recursos naturais sejam desperdiçados. Associado a esse desperdício vem o fator 
financeiro, já que as despesas mensais relativas à água e energia elétrica estão entre os maiores gastos da Administração, de acordo com dados extraídos do Painel de Custos do Ministério do Planejamento, figura 1.

Figura 1: Montante dos gastos mensais de água e esgoto e energia

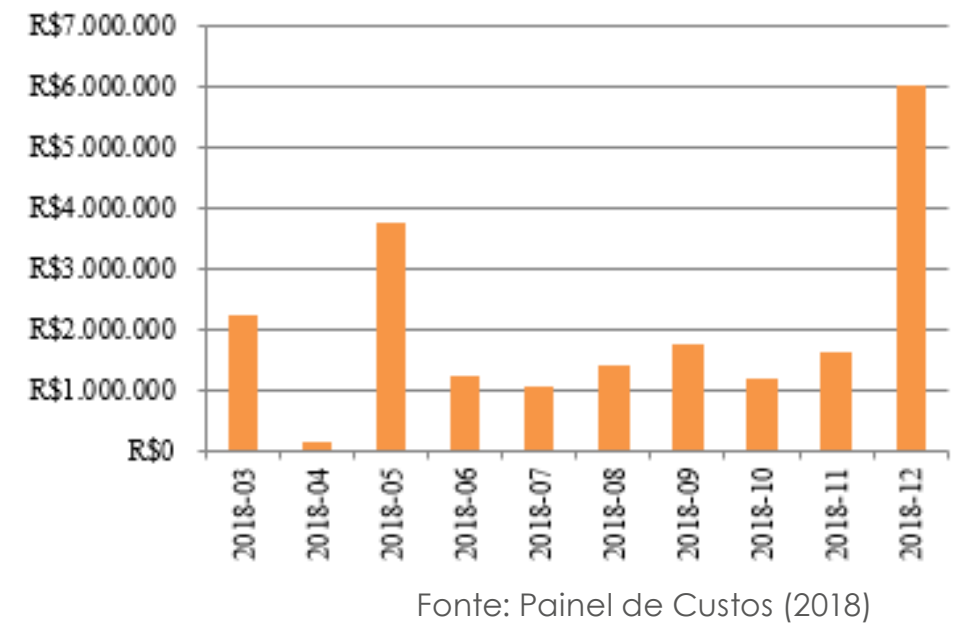

- DESPESA TOTAL

Esta valoração do serviço de captação e abastecimento de água nos permitiu propor medidas que ajudarão a combater o desperdício, considerando a sustentabilidade, proporcionando uma possível redução de despesas mensais da Instituição, além de ser possível evidenciar o perfil de consumo de água realizado no Campus, por meio de coleta de dados de medidores instalados no sistema.

Não somente na UFPB, mas também, de uma maneira geral, em virtude de um contingenciamento energético e financeiro, associada à questão sustentável do uso dos recursos naturais, de barateamento de tecnologias e equipamentos, abrem um campo de investigação e recomendações de uso racional destes recursos.

\section{REVISÃO BIBLIOGRÁFICA}

\section{ÁGUA E O MEIO AMBIENTE}

A água é componente fundamental de dinâmica da natureza, impulsiona todos os ciclos, sustenta a vida e é o solvente universal. Sem água, a vida na Terra seria impossível, ela é o recurso natural mais importante que participa e dinamiza todos os ciclos ecológicos; os sistemas aquáticos têm uma grande diversidade de espécies úteis ao homem e que são também parte ativa e relevante dos ciclos biogeoquímicos e da diversidade biológica do planeta Terra (TUNDISI, 2003).

Atualmente, com a degradação cada vez maior do meio ambiente, que vem se refletindo nos custos do tratamento das águas superficiais, as águas subterrâneas se constituem uma alternativa bastante vantajosa do ponto de vista 
econômico e sanitário para o suprimento das comunidades, além da possibilidade de localização da captação próxima à área de consumo, o que facilita o controle operacional.

\section{EXPLORAÇÃO DA ÁGUA SUBTERRÂNEA}

No Brasil, 15,6\% dos domicílios utilizam, exclusivamente, água subterrânea, $77,8 \%$ usam rede de abastecimento de água e 6,6\% usam outras formas de abastecimento (IBGE, 2002). Os reservatórios de águas subterrâneas são chamados de lençóis, essas águas podem estar acumuladas em dois tipos de lençóis: o freático e o artesiano.

Na UFPB Campus I a captação de água subterrânea é realizada em aquíferos que são formações geológicas constituídas por rochas capazes de armazenar e transmitir quantidades significativas de água. Os três poços artesianos que serão investigados neste estudo possuem diâmetro de médio de 6 polegadas e profundidade média de 120 metros. Para que a água dos poços seja captada e aduzida á superfície utilizam-se bombas submersas que são responsáveis pelo recalque por meio de tubos redutores que deságuam em um reservatório enterrado, cisterna que será recalcada para um reservatório elevado e a partir daí, por gravidade, seguir para rede de abastecimento até o consumo final.

Neste âmbito, abaixo, caracterizam-se os poços objeto de estudo:

- Poço 01 - Localizado junto a Capela Universitária:

Poço tubular, artesiano, de 6 polegadas de diâmetro com profundidade aproximada de 133 metros, cuja bomba encontra-se instalada numa profundidade de 84 metros, com potência de $15 \mathrm{CV}$.

- Poço 02 - Localizado adjacente ao Restaurante Universitário:

Poço tubular, artesiano de 6 polegadas de diâmetro com profundidade aproximada de 153 metros, cuja bomba submersa encontra-se instalada numa profundidade de 78 metros, com potência de $15 \mathrm{CV}$.

- Poço 03 - Localizado dentro do Restaurante Universitário:

Poço tubular, artesiano de 4 polegadas de diâmetro com profundidade aproximada de 80 metros, cuja bomba submersa encontra-se instalada numa profundidade de 45 metros, com potência de $5 \mathrm{CV}$. 


\section{SUSTENTABILIDADE AMBIENTAL}

A sustentabilidade ambiental está relacionada com uso adequado e racional dos recursos naturais, levando em consideração sua capacidade limitada. Conforme preconiza o artigo 225, da Constituição Brasileira, de 1988, determina: "todos têm direito ao meio ambiente ecologicamente equilibrado, bem de uso comum do povo e essencial à sadia qualidade de vida, impondo-se ao Poder Público e à coletividade o dever de defendê-lo e preservá-lo para às presentes e futuras gerações".

Para ser sustentável, o desenvolvimento deve implementar eficiência econômica, proteger e restaurar os sistemas ecológicos e melhorar a qualidade de vida das populações, de acordo com Kats (1998).

\section{REDE DE DISTRIBUIÇÃO DA UFPB}

A rede de distribuição é a unidade do sistema responsável pelo transporte da água, desde os reservatórios de distribuição até pontos de consumo em quantidade e com pressões compatíveis ao uso estabelecido.

Dentro do Campus da UFPB possuímos tubulações de diâmetros variáveis, desde tubulações de $250 \mathrm{~mm}$, até ramais com $20 \mathrm{~mm}$. Tipicamente o sistema de distribuição tem a topologia mista, ou seja, apresenta uma associação entre a ramificada e a malhada, formando um anel que circula todo o campus, além de possuir derivações para atender principalmente novas edificações que surgiram no decorrer dos anos devido, principalmente, à expansão do Campus.

Diversos são os materiais constituintes dos tubos da rede, temos troncos principais de ferro fundido, PVC e amianto, e redes secundárias em PVC. Não existe padronização dos materiais das tubulações, fato este justificável, principalmente, pela idade elevada do sistema de distribuição do Campus, coexistindo materiais de idades e tecnologias diferentes.

\section{CUSTO DA ENERGIA}

Os consumidores de energia elétrica pagam um valor correspondente à quantidade de energia elétrica consumida, medida por meio de equipamentos que registram a potência consumida, no mês anterior, estabelecida em quilowatthora (kWh) e multiplicada por um valor unitário, denominado tarifa, medido em reais por quilowatt-hora ( $R \$ / k W h)$.

A Energisa é a empresa responsável pelo fornecimento e distribuição de energia elétrica no estado da Paraíba. A UFPB - Campus I, como entidade pública, e cliente desta concessionária, está enquadrada no grupo A4, pois recebe energia 
de uma fonte de tensão de entre 2,3 a $25 \mathrm{KV}$, possuindo uma tensão contratada de $13,8 \mathrm{KV}$, estando inserida na modalidade horossazonal verde.

\section{O VALOR DA ÁGUA}

De acordo com Magalhães Júnior (2007) organismos internacionais têm proposto a adoção da cobrança pelo uso da água como a mais importante recomendação política aos governos nacionais, visando racionalizar o uso da água e gerar receitas para conservação e recuperação de sua qualidade.

O artigo 21 da Constituição Federal descreve que a competência da União para "instituir sistema nacional de gerenciamento de recursos hídricos" e "definir critérios de outorga de direitos de seu uso", já no artigo 22 institui que a União tem competência privativa para legislar sobre águas.

A Universidade Federal da Paraíba, como órgão público, usuária dos serviços prestados pela CAGEPA está sujeita a sua estrutura tarifária, sendo cobrado pelo volume de água consumida, bem como pelo serviço de coleta de esgoto sanitário. Vale ressaltar que na categoria pública, a taxa de esgoto corresponde a 100\% da tarifa de água, conforme quadro 1.

Quadro 1: Valor do metro cúbico de água

\begin{tabular}{|c|c|c|}
\hline FAIXA DE CONSUMO $\left(\mathrm{m}^{3}\right)$ & VALOR DA ÁGUA $\left(\mathrm{R} \$ \mathrm{~m}^{3}\right)$ & VALOR DO ESGOTO $\left(\mathrm{R} \$ / \mathrm{m}^{3}\right)$ \\
\hline até $10 \mathrm{~m}^{3}$ & 76,83 & 76,83 \\
\hline excedente de $10 \mathrm{~m}^{3}$ & 12,89 & 12,89 \\
\hline
\end{tabular}

Fonte: CAGEPA (2018)

Atualmente, o usuário paga apenas o custo do tratamento e da distribuição. A cobrança pelo uso da água está inserida em um princípio geral do Direito Ambiental que impõe àquele que, potencialmente, auferirá os lucros com a utilização dos recursos ambientais, o pagamento dos custos.

\section{METODOLOGIA}

A pesquisa é caracterizada de caráter bibliográfica e experimental, pois busca o aprimoramento de ideias e a identificação de ações que contribuem para o gerenciamento eficiente do consumo de água e energia, além gerar uma reflexão sobre as sobre as práticas sustentáveis no ambiente educativo, incrementando o relacionamento entre diversos sistemas de conhecimentos, contemplando a interdisciplinaridade e o as relações entre o social e o meio natural.

Este estudo tem como objetivo principal investigar o consumo de água associado ao gasto energético referente ao funcionamento dos conjuntos elevatórios responsáveis pela captação de água dos poços artesianos responsáveis 
pelo abastecimento da Universidade Federal da Paraíba - Campus I. Para que consigamos alcançar esse propósito deve-se:

- Especificar o funcionamento do sistema de captação de águas subterrâneas;

- Caracterizar o modo de distribuição de água dentro do Campus l;

- Verificar o consumo de energia e o valor gasto relacionado à captação de água subterrânea utilizada para o abastecimento do Campus I da UFPB;

- Determinar o consumo de água associado ao custo energético.

Estando o estudo enquadrado como um projeto de pesquisa, buscou-se contribuir para a produção, apropriação e aplicação do conhecimento embasado no rigor metodológico e nos fundamentos científicos, com foco na pesquisa aplicada e a proposição de inovações e aperfeiçoamentos tecnológicos para a resolução de situações e problemas concretos, sendo, pois, classificada como pesquisa empírica, já que os resultados e conclusões serão analisados a partir de coleta de dados in loco, através de uma abordagem quantitativa, e a partir daí apontadas sugestões de gerenciamento e controle dos gastos e preservação dos recursos naturais e financeiros, consoante ao que exige o Governo Federal com o contingenciamento das despesas ordinárias do Executivo Federal e por meio da Emenda Constitucional 95/2016.

O campo da pesquisa está situado no Campus I da UFPB, na Cidade Universitária. O abastecimento de água no Campus I da Universidade Federal da Paraíba - UFPB é realizada por meio de captação de águas subterrâneas, cuja captação é promovida por conjuntos elevatórios que funcionam continuamente, que transportam a água captada para uma cisterna localizada junto ao Restaurante Universitário que a partir de dois conjuntos elevatórios recalcam água para o reservatório elevado, localizado no mesmo local, e por meio de gravidade o abastecimento é realizado em todo o Campus, de acordo com a figura 2.

Figura 2: Localização dos Poços e Reservatórios

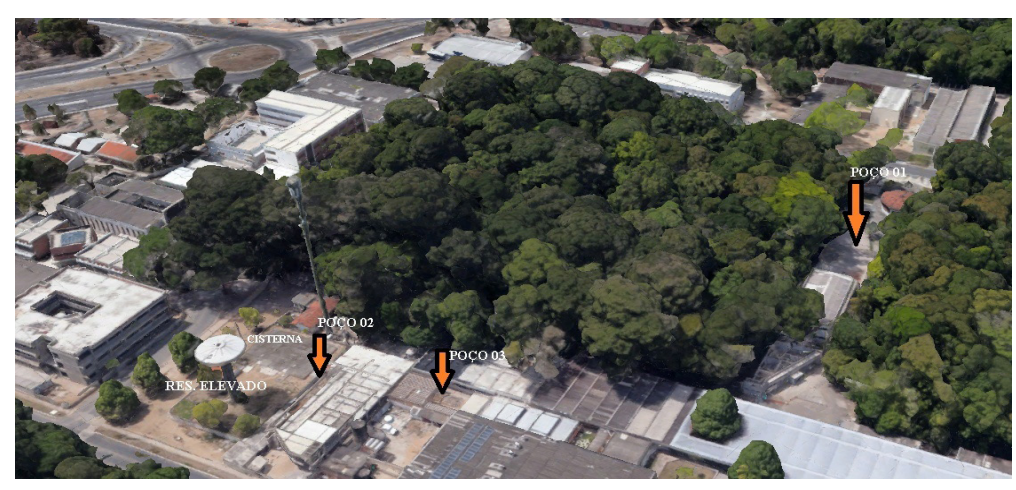

Fonte: Google Earth (2018) 
Apesar da UFPB possuir outros poços dentro do Campus l, a escolha deste local para estudo deve-se ao fato de concentrar os reservatórios que abastecem todo o Campus, tanto a cisterna que recebe água dos poços, como o elevado que a distribui. Vale destacar que o ramal de entrada da CAGEPA encontra-se situado neste local, possuindo diâmetro de $250 \mathrm{~mm}$, desaguando diretamente na cisterna.

A obtenção dos resultados foi feita por meio da instalação de um aparelho do tipo digital com sistema de registro de leituras automáticos implantado no alimentador de energia principal do ramal de entrada que alimenta os quadros de comando dos conjuntos elevatórios, registrando entre outras grandezas a potência ativa durante um período de 30 dias, a partir do dia 07 de fevereiro de 2019, período este coincidente com início do período letivo, pois assim teríamos uma expectativa de consumo para o Campus I em pleno funcionamento, além de ser um período verão no qual o consumo de água tende a ser mais elevado do que em outras estações do ano.

No cálculo do custo energético referentes à potência demandada para funcionamento dos motores, especificamente a potência ativa medida em quilowatts hora ( $\mathrm{kWh}$ ), separando-se em consumo de ponta, referente ao período do dia compreendido entre às 17:30 horas e às 20:30 horas de segunda a sextafeira, excetos sábado, domingos e feriados, e consumo fora ponta nos demais horários. A partir destes consumos e aplicando-se os valores do kWh praticado pela concessionária local, além dos impostos chegou-se ao custo energético mensal para abastecimento do Campus I. Já para estimar volume de água referente ao período em análise, chegou-se ao resultando realizando inferências entre o custo energético e o valor do metro cúbico de água praticado pela CAGEPA.

Em seguida foi feito comparativo do consumo estimado com a Universidade Federal de Campina Grande - UFCG, Instituição com uma estrutura administrativa e organizacional semelhante a UFPB além de possuir os mesmos parâmetros de tarifação de água. Com esse comparativo, foi possível confrontar os consumos anuais por aluno matriculado em relação ao desembolsado, além de possibilitar ter a conclusão que na UFPB ocorre realmente um desperdício hídrico.

\section{RESULTADOS E DISCUSSÕES}

O consumo de energia está diretamente relacionado com o volume de água captada e distribuída, sendo fortemente influenciada por alguns fatores, como o valor da tarifa cobrada, as características dos equipamentos hidrossanitários e mecânicos, aspectos climáticos e operação do sistema de abastecimento.

No quadro 2 são apresentados os dados referentes ao consumo mensal compreendido entre 07/02/2019 a 08/03/2019, o consumo geral refere-se ao total com separação dos postos tarifários, ponta e fora ponta. 
Quadro 2: Consumos mensal postos tarifários

\begin{tabular}{|c|c|c|c|c|}
\hline MÊS & $\begin{array}{c}\text { CONSUMO FORA } \\
\text { PONTA }(\mathrm{kWh})\end{array}$ & $\begin{array}{c}\text { CONSUMO PONTA } \\
(\mathrm{kWh})\end{array}$ & $\begin{array}{c}\text { \% REFERENTE AO TOTAL } \\
\text { - FORA PONTA }\end{array}$ & $\begin{array}{c}\text { \% REFERENTE AO } \\
\text { TOTAL - PONTA }\end{array}$ \\
\hline Fevereiro & $2.724,10$ & $\mathrm{R} \$ 285,90$ & $70,11 \%$ & $7,36 \%$ \\
\hline MarçO & 812,70 & $\mathrm{R} \$ 62,80$ & $20,92 \%$ & $1,62 \%$ \\
\hline TOTAL & $3.536,80$ & 348,70 & $91 \%$ & $9 \%$ \\
\hline
\end{tabular}

Fonte: Autor, 2019

Uma das possíveis causas do consumo elevado de energia deve-se ao fato dos motores estarem superdimensionados, sendo esta uma das causas mais comuns para operação ineficiente do sistema, podendo ocasionar estimativas de consumo de água maiores que as reais.

Em seguida, na figura 3, são apresentados os consumos diários separando os postos tarifários, no qual se podem verificar quais os dias de maiores consumos em cada posto. Neste sentido a análise dos resultados diários foi extraída quais dias possuem maior consumo de ponta, ou seja, é possível identificar os dias nos quais houve maior utilização do sistema entre as 17:30 horas e 20:30 horas, bem como se pagou a mais neste horário diferenciado.

Figura 3: Consumo diário proporcionalizado

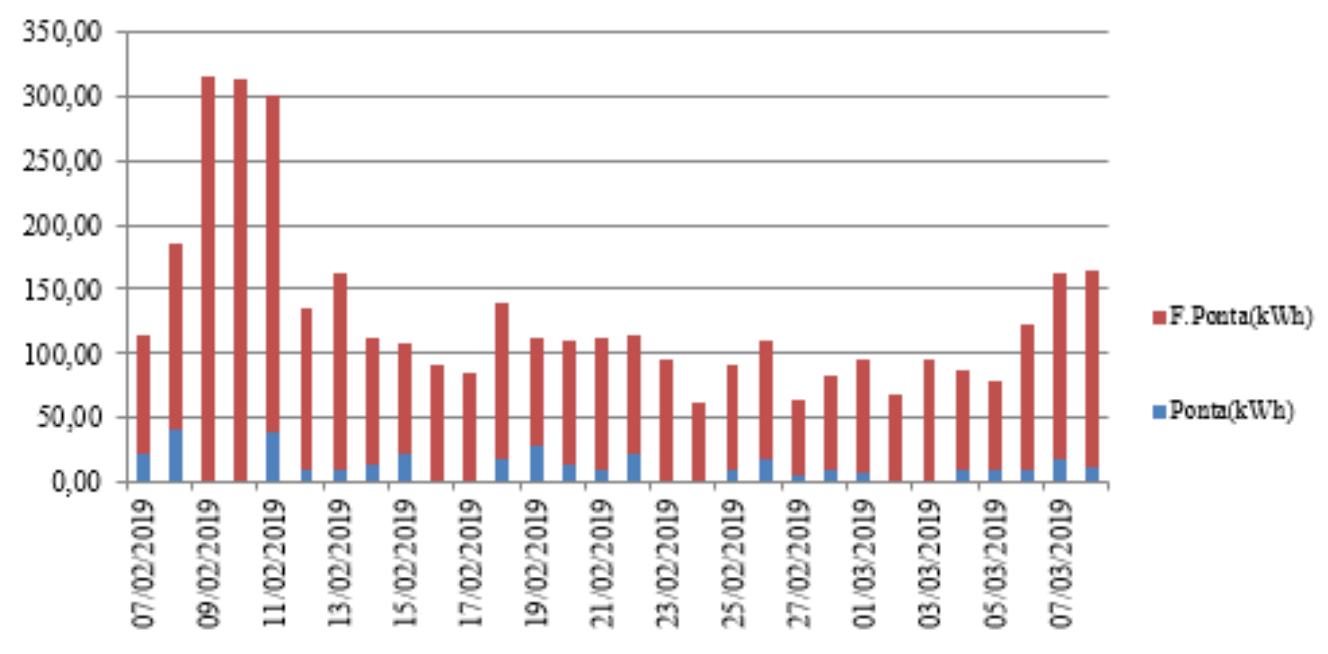

Fonte: Autor, 2019

Nos dias 09 e 10 de fevereiro foram os que apresentaram maiores consumos. Apesar dos referidos dias serem sábado e domingo respectivamente, tal consumo deve-se ao fato, provavelmente, do sistema estar operando em modo manual, ou seja, com os motores ligados de maneira contínua durante as 24 horas, ocasionando um consumo de energia praticamente 3 vezes maior que nos demais dias, o que corrobora com esta indicação é o fato dos consumos serem praticamente idênticos.

O dia que apresentou menor desvio absoluto em relação à média foi o dia 06 de março de 2019, cujo valor foi de 6,12. Em seguida, é apresentado o consumo 
horário através do perfil de consumo, figura 4, representado pela curva onde é possível visualizarmos o comportamento do sistema ao longo do dia.

Figura 4: Perfil de consumo dia 06/03/2019

\section{PERFIL DE CONSUMO}

DIA PADRÃO 06-03-19

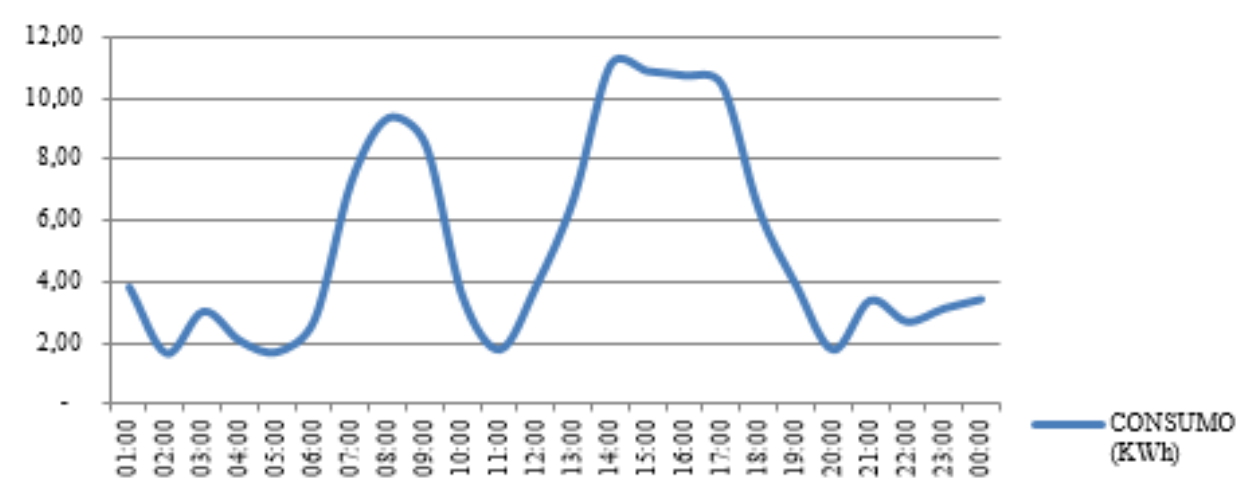

Fonte: Autor, 2019

Através da análise do gráfico, pode-se verificar que a consumo começa a aumentar a partir das 5:00 horas chegando ao pico de consumo entre 8:00 e 9:00 horas. A partir das 9:00 horas o consumo começa a diminuir chegando a valores mínimos por volta das 11:00 horas. Após as 11:00 horas o consumo começa novamente a subir atingindo o ápice às 15:00 horas. No intervalo entre às 15:00 e às 17:00 horas o consumo permanece praticamente constante, vindo a decair gradualmente até as 20:00 horas, apresentando pequenos aumentos de consumo até as 00:00 horas.

Podemos notar que os períodos de maior consumo coincidem com o funcionamento da Instituição, registrando seus maiores valores no início da manhã e da tarde, justamente representando o intervalo de maior fluxo de pessoas e utilização dos serviços da Instituição, vindo a cair significativamente em horários de fluxo reduzido, a exemplo do noturno.

\section{CUSTO DE ENERGIA PARA ABASTECIMENTO}

Os gastos de água e energia devem ser interpretados como dados interrelacionados e não de forma única, separada. A energia é necessária para captar e distribuir a água através dos sistemas de abastecimento, tornando a água disponível nos pontos de consumo.

Para serem obtidos os custos de energia referentes aos consumos medidos durante o período monitorado, aplicamos o valor do kWh fornecido pela Energisa, além dos impostos federais, como o PIS e COFINS, com porcentagem de $0,9905 \%$ e $4,5624 \%$ do valor do produto entre consumo e valor do $\mathrm{kWh}$ respectivamente. Existe 
também o imposto estadual ICMS no valor de $25 \%$ do produto entre consumo e valor do kWh, conforme apresentado no quadro 3.

Quadro 3: Valor da energia gasta para abastecimento

\begin{tabular}{|c|c|c|c|c|c|c|c|}
\hline HORÁRIO & $\begin{array}{c}\text { CONSUMO } \\
\text { MEDIDO - } \\
\text { kWh }\end{array}$ & $\begin{array}{c}\text { VALOR DA } \\
\text { TARIFA - kWh }\end{array}$ & VALOR TOTAL & $\begin{array}{c}\text { ICMS (R\$) } \\
\mathbf{2 5 \%}\end{array}$ & $\begin{array}{c}\text { PIS (R\$) } \\
(\mathbf{0}, \mathbf{9 9 0 5 \% )}\end{array}$ & $\begin{array}{c}\text { COFINS (R\$) } \\
(\mathbf{4}, 5624 \%)\end{array}$ & $\begin{array}{c}\text { TOTAL } \\
\text { MENSAL }\end{array}$ \\
\hline $\begin{array}{c}\text { FORA } \\
\text { PONTA }\end{array}$ & $3.536,80$ & $\mathrm{R} \$ 27,56$ & $\mathrm{R} \$ 97.476,12$ & $\mathrm{R} \$ 24.369,03$ & $\mathrm{R} \$ 965,50$ & $\mathrm{R} \$ 4.447,25$ & $\mathrm{R} \$ 127.257,90$ \\
\hline PONTA & 348,70 & $\mathrm{R} \$ 82,36$ & $\mathrm{R} \$ 28.720,62$ & $\mathrm{R} \$ 7.180,16$ & $\mathrm{R} \$ 284,48$ & $\mathrm{R} \$ 1.310,35$ & $\mathrm{R} \$ 37.495,61$ \\
\hline TOTAL & $\mathbf{3 . 8 8 5 , 5 0}$ & $\mathrm{R} \$ 109,93$ & $\mathrm{R} \$ 126.196,74$ & $\mathrm{R} \$ 31.549,19$ & $\mathrm{R} \$ 1.249,98$ & $\mathrm{R} \$ 5.757,60$ & $\mathrm{R} \$ 164.753,51$ \\
\hline
\end{tabular}

Fonte: Autor, 2019

O valor referente ao gasto energético dos sistemas elevatórios do Campus I foi de $R \$ 164.753,51$, equivalente a aproximadamente $16 \%$ do valor da fatura do mês de março 2019, ou seja, cerca de 16\% da energia gasta no Campus refere-se ao funcionamento dos motores responsáveis pelo abastecimento de água para o funcionamento da Instituição.

\section{ESTIMATIVA DO CONSUMO DE ÁGUA}

Para calcular a estimativa do consumo de água referente ao gasto energético necessário para o funcionamento dos sistemas de recalque, foram realizadas inferências entre o valor do metro cúbico praticado pela CAGEPA e o valor de energia durante o período monitorado.

De posse do valor do consumo de energia dos poços nos 30 dias monitorados, pode-se inferir, a partir da tarifa do metro cúbico praticado pela Cagepa, o volume de água utilizada para o abastecimento do Campus, através dos poços artesianos, durante este período. Foi obtido um volume de água de 12.781,50 $\mathrm{m}^{3}$ de água utilizada para o abastecimento do Campus I exclusivamente dos poços artesianos (quadro 4), valor este compatível com os volumes apresentado no mês de agosto de 2018, cujo total da fatura foi de $R \$ 329.982,98$, correspondendo a $R \$ 164.991,49$ ao consumo de água, e o mesmo valor para coleta de esgotos, representando um volume de $12.804 \mathrm{~m}^{3}$ de água fornecida.

Quadro 4: Estimativa do volume de água

\begin{tabular}{|c|c|}
\hline \multicolumn{2}{|c|}{ RELAÇÃO CUSTO DE ENERGIA X VOLUME DE ÁGUA } \\
\hline CUSTO DO m ${ }^{3}$ DE ÁGUA (R\$/m³) - CAGEPA & 12,89 \\
\hline CUSTO MEDIDO REFERENTE AO ABASTECIMENTO UFPB - CAMPUS I & R\$ $164.753,51$ \\
\hline VOLUME DE ÁGUA ESTIMADO $\left(\mathrm{m}^{3}\right)$ & $12.781,50$ \\
\hline
\end{tabular}

Fonte: Autor, 2019 
Extrapolando-se o valor estimado para captação e distribuição de água subterrânea, percebe-se que a UFPB economizaria por mês $R \$ 329.507,02$, que seria o valor faturado pela CAGEPA (água+esgoto) caso fosse usado somente água por ela fornecida, gerando um montante anual de aproximadamente $\mathrm{R} \$ 3.954 .084,24$.

Comparativamente podemos analisar a Universidade Federal de Campina Grande (UFCG) organização com estrutura administrativa semelhante a UFPB e incluída numa região comrecursos hídricos menos abundantes que aregiãolitorânea, possuindo os mesmos parâmetros de cobrança da tarifa de água, que em 2014 passou por um processo de reestruturação do sistema de abastecimento de água de todo o Campus, visando combater as perdas, os desperdícios, proporcionando o uso racional e controlado deste recurso. Inicialmente o consumo de água até o ano de 2014 apresentava valores anuais crescentes, porém a partir da implantação do sistema, em 2015, começou-se a verificar a redução só no primeiro ano de cerca de $50 \%$ no consumo do ano anterior, e nos anos subseqüentes ocorrendo redução gradativa. Esse comportamento é consequentemente refletido nos valores das faturas pagas, gerando uma economia, até o momento, de aproximadamente $\mathrm{R} \$$ 1,5 milhão (UFCG, 2019), conforme a figura 5.

Figura 5: Histórico de faturas de água - UFCG

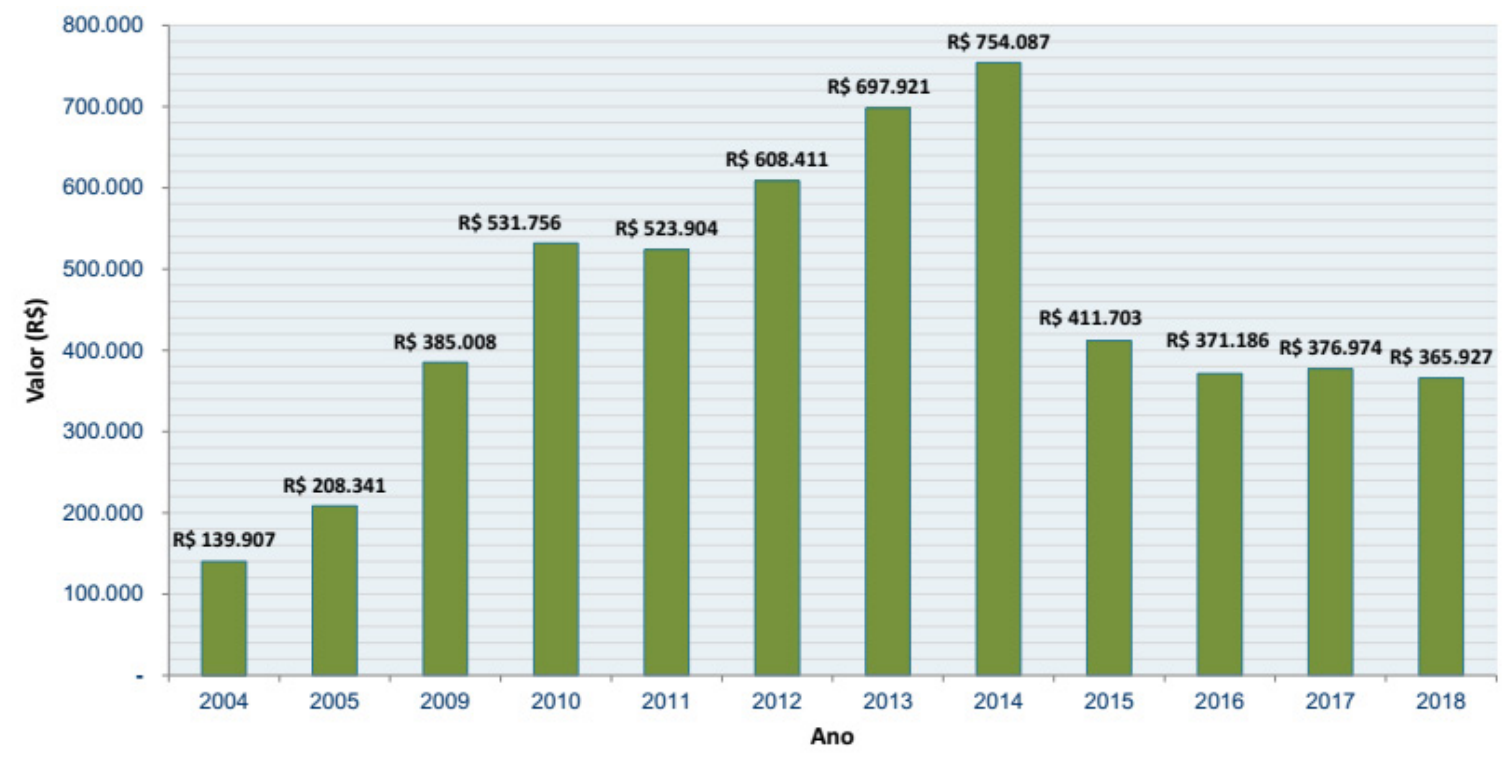

Fonte: UFCG, 2019

Vale salientar que o UFCG utiliza apenas água da CAGEPA como fonte de abastecimento, não possuindo poços artesianos no Campus. Conforme o site do UOL (2019), os dados do Ranking Universitário da Folha o número de alunos matriculados na UFCG no ano 2018 foi de 15.456 e o valor gasto com água foi de R\$365.927, obtendo-se uma relação anual de $\mathrm{R} \$ 23,67$ por aluno matriculado, já na UFPB, no mesmo período, possuía 29.993 alunos matriculados e gastou nos últimos doze meses $R \$ 1.588 .901,03$, gerando uma relação de $\mathrm{R} \$ 52,98$ por aluno matriculado, ou

\section{INTER/SCIENTIA}

REVISTA INTERSCIENTIA | V. 7 | N. 1 | P. 39-53 | JAN-JUN/2019 
seja, mais que o dobro gasto pela UFCG. Ressalta-se que caso a UFPB não optasse pelo abastecimento complementar por poços artesianos o valor da relação custo anual por aluno seria de $\mathrm{R} \$ 184,81$ por aluno matriculado, mostrando-se um sistema bastante ineficiente quando comparado com o da UFCG, segundo figura 6.

Figura 6: Valor per capita anula por aluno matriculado

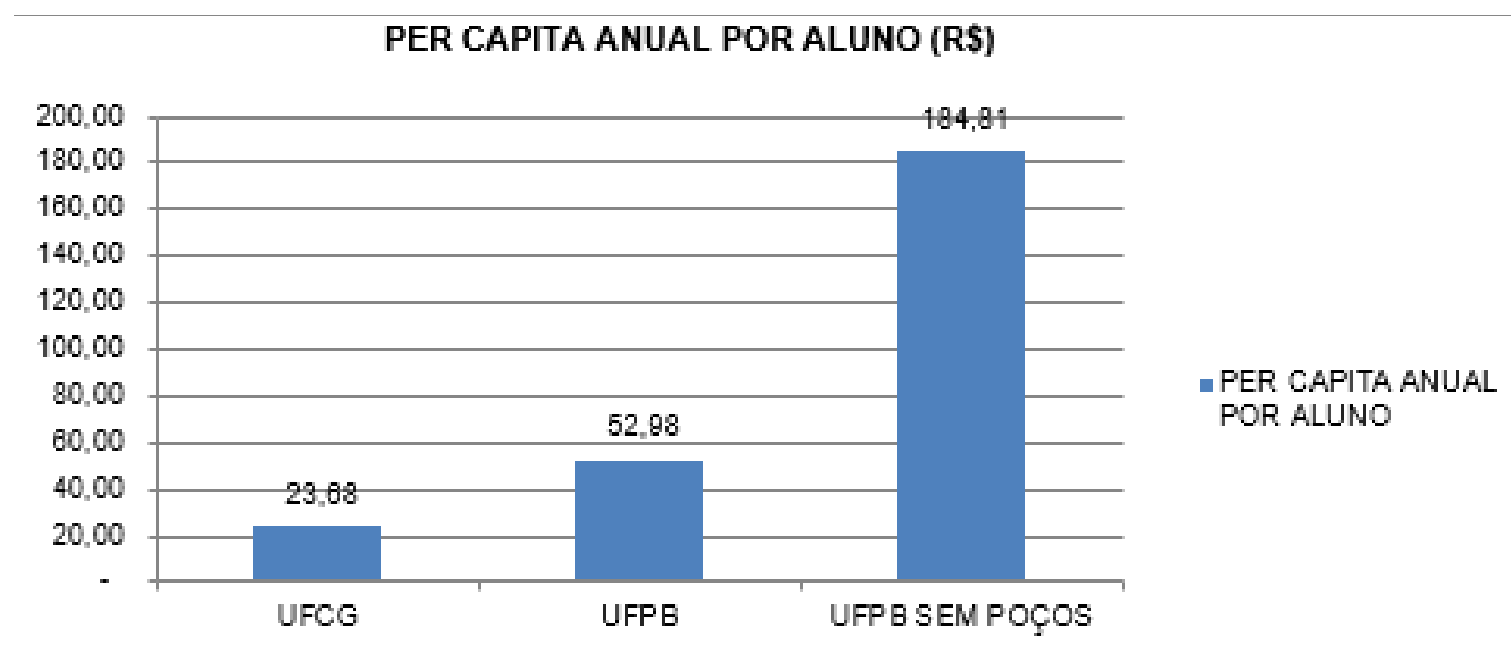

Fonte: Autor, 2019

Portanto, é necessário que a Instituição desenvolva um ciclo de atualização constante, percebendo e incorporando contribuições internas e externas no processo de inovação, visando o reaprendizado e possibilitando a prestação de um serviço de melhor qualidade a comunidade.

\section{CONSIDERAÇÕES FINAIS E RECOMENDAÇÕES}

Neste trabalho, buscou-se estimar o consumo de água para abastecimento captada dos poços artesianos e distribuída dentro do Campus I da UFPB, sendo que está investigação se deu por meio do monitoramento do consumo de energia dos motores responsáveis pelo suprimento hídrico.

Os conjuntos elevatórios responsáveis pela captação e distribuição de água no objeto de estudo há vários anos não passam por manutenções preventivas, periódicas, dos motores e do sistema elétrico, pois tal ação irá contribuir para um aumento da vida útil. A melhor maneira de prevenir defeitos é seguir as instruções de manutenção do fabricante e observar o desempenho normal do motor, observando se o motor esta com funcionamento anormal, emitindo ruídos excessivos, alta temperatura e vibração. Caso os motores vierem a quebrarem a melhor opção é procurar uma empresa especializada que altere minimamente às características originais do motor, pois reparos mal realizados as características elétricas, magnéticas e mecânicas dos motores são muitas vezes alteradas, aumentando as perdas da máquina. 
Outra providência necessária é referente ao estudo visando o redimensionamento do sistema, com a possibilidade de futuramente substituir os motores atuais por máquinas mais modernas, com rendimentos melhores, menores consumos de energia e com potência compatível com a sua utilização.

Para maior controle do funcionamento do sistema elevatório é fundamental uma operação mais atuante, verificando as falhas e intervindo preventivamente nas suas ocorrências. Alternativamente, pode-se adotar um sistema de monitoramento e operação automatizada, onde a dependência da operação humana se torna secundária, tornando o sistema mais confiável com monitoramento durante as 24 horas/dia, permitindo programação para que o reservatório central esteja cheio antes do início do horário de ponta, com o intuito de manter os motores desligados durante as 3 horas na qual a tarifa é mais cara.

Outro ponto a se destacar é o controle das perdas físicas sendo necessário que seja realizado o cadastro de toda rede de distribuição existente contendo informações como: diâmetro, tipo de material e extensão da tubulação. Assim, as perdas de água na forma de vazamentos, desperdícios do consumidor e distribuição ineficiente afetam diretamente a quantidade de energia necessária para fazer a água chegar ao consumidor.

Aliado a este estudo poderá ser providenciado junto ao setor competente da UFPB providências no sentido de serem substituídos gradativamente os aparelhos sanitários, louças e metais, por equipamentos mais modernos, mais eficientes e que consumam menos água. A utilização de arejadores em torneiras, redutores de pressão, vasos sanitários com acionamento duplo, torneiras com fechamento automático permitirão redução substancial da demanda de água, investimento que além de trazer conforto ao usuário trará benefícios sustentáveis a Instituição.

A crise no abastecimento d'água mostra a necessidade de buscar alternativas ao atual estado de uso deste recurso, que contribuam para o uso eficiente e sustentável da água. A substituição de fontes se mostra como uma importante alternativa no atendimento a demandas menos restritivas. A captação e utilização de águas pluviais apresentam-se como tecnologia moderna e viável quando associada a novos conceitos e técnicas construtivas, alternativa para o abastecimento descentralizado.

Uma nova alternativa para suprimento de parte das demandas do Campus seria a utilização de águas provenientes dos aparelhos de ar condicionado. Segundo informações do setor responsável pela manutenção e instalação destes equipamentos, Seção de Equipamentos da Prefeitura Universitária, existem aproximadamente 4.500 máquinas instaladas de diversas potências apenas no Campus I, sem nenhum tipo de sistema de reaproveitamento deste resíduo para fins não potáveis.

Práticas educativas para uso sustentável da água podem ser disseminadas no ambiente Institucional, por ser essencialmente educativo e formador de 
cidadãos, visando o uso racional deste recurso criando condições necessárias para a participação de diversos grupos sociais, tanto na formulação de políticas públicas, quanto na criação e implementação de decisões que interfiram na qualidade do ambiente em geral, particularmente dos recursos hídricos.

\section{REFERÊNCIAS}

BRASIL. Constituição (1988). Constituição da República Federativa do Brasil. Disponível em: <http://www.planalto.gov.br/ccivil_03/Constituicao/Constituicao.htm>. Acesso em 06 de novembro de 2018.

CAGEPA. Estrutura tarifária. Disponível em: <https://agenciavirtualcagepa.gsan. com.br/gsan/exibirConsultarEstruturaTarifariaPortalCagepaAction.do> . Acesso em: 08 nov. 2018.

INSTITUTO BRASILEIRO DE GEOGRAFIA E ESTATÍstICA (IBGE). Pesquisa Nacional por Amostra de Domicílios - 2002. Rio de Janeiro: IBGE, 2002b. CDROM.

KATS. G. "Measuring and verifying climate change emissions reductions". Anais do 1998 ACEEE Summer study on energy efficiency in buildings, 1998.

LEMOS, Haroldo Mattos de. O Século 21 e a Crise da Água. São Paulo: Agência Estado, Caderno Ciência, 2003.

MAGALHÃES JÚNIOR, A. P. Indicadores ambientais e recursos hídricos: realidade e perspectivas para o Brasil a partir da experiência francesa. Rio de Janeiro: Bertrand Brasil, 2007.

PAINEL DE CUSTOS - Ministério do Planejamento - Disponível em: <http:// paineldecusteio.planejamento.gov.br/custeio.html>. Acesso em: 05 de agosto de 2018.

PREFEITURA UNIVERSITÁRIA - UFCG. Consumo de água 2019. Disponível em: < http:// WwW.prefeitura.ufcg.edu.br/images/agua/PU-Dados---Consumo-de-gua-201915milho.pdf>. Acesso em 14 de maio de 2019.

TUNDISI, J. G.. Água no século XXI: enfrentando a escassez. São Carlos: Rima, 2003.

Recebido em: 01/06/2019.

Aceito em: 17/06/2019. 